\title{
New Approaches to Disease Vector Control in the Context of Sustainable Development'
}

\section{Novas Abordagens ao Controle de Vetores de Doenças no Contexto do Desenvolvimento Sustentável}

\author{
Robert Bos ${ }^{2}$ \\ BOS, $R$. New Approaches to Disease Vector Control in the Context of Sustainable \\ Development. Cad. Saúde Públ., Rio de Janeiro, 8 (3): 240-248, jul/set, 1992.
}

Faced with problems that are specific to the health sector and ones associated with issues of sustainability, programmes for the control of vector-borne diseases are increasingly resorting to environmental management measures to reduce populations of disease vectors as part of an integrated control approach. The broader problems on the interface between environment and development that need to be addressed in the context of vector control include accelerated development of natural resources, demographic changes in rural populations and rapid urbanization. Disease vectors need to be recognized as biological risk factors to human health in the environment, and for a sustainable implementation of vector control measures, these should be made an integral part of the development process. This requires modifications in the policy framework, expansion of our knowledge base, development of operational methods and techniques and a shift in emphasis in training and education.

Keywords: Vector-Borne Diseases; Environment; Development Policies; Sustainable Development

\section{INTRODUCTION}

Since the beginning of this century the control of disease vectors has been an important component of strategies in the fight against vector-borne diseases. There has been an evolution in the nature of the control methods over time as epidemiological situations changed, new control technologies developed and new constraints arose. The focus on source reduction and species sanitation in the first half of the century shifted dramatically to chemical methods of

\footnotetext{
'The opinions expressed in this paper are the author's only and do not necessarily reflect the policies of the World Health Organization or of the other three UN agencies participating in PEEM.

${ }^{2}$ Community Water Supply and Sanitation Unit, and Secretary, joint WHO/FAO/UNEP/UNCHS Panel of Expers on Environmental Management for Vector Control, PEEM Secretariat, World Health Organization, 1211 Geneva 27, Switzerland.
}

control with the advent of affordable residual insecticides in the 1940s and 1950s. By the middle of the 1970 s, however, the problems that inevitably arose from the almost exclusive reliance on house spraying campaigns and urban larviciding led to a reconsideration of the existing options, and to fresh thinking about the development of new methods and tools. The 1980 s witnessed a move away from the universal application of insecticides towards more balanced, integrated control efforts with increased emphasis on methods of environmental modification and manipulation and personal protection adapted to site-specific epidemiological and ecological conditions.

Vector-borne diseases not only continue to be an important public health problem in many countries in the tropical and subtropical zones, but several of them are spreading and in many endemic areas their transmission is intensifying. Global figures show at least a stagnation in the success of 
efforts to control them, but in many parts of the world there is gross under-reporting of disease incidence and the estimates are not reliable. The malaria situation illustrates this point. An estimated two billion people are estimated to be at risk; some $\mathbf{2 7 0}$ million are estimated to actually carry the parasite at any one time; annually, an estimated 110 million clinical cases result from infection; and estimates of annual mortality rates fluctuate between 1 and 2 million (WHO, 1991). Considering that some $80 \%$ of the malaria cases occur in sub-Saharan Africa, where health authorities lack the resources to mount effective control programmes, let alone carry out reliable epidemiological monitoring, such estimates have to be taken with a lot of reservations.

The problems faced by vector-borne disease control programmes today can for the purpose of this Conference be divided into health sector specific constraints and problems arising from global trends on the interface between socio-economic development and the environment.

\section{PROBLEMS CONFINED TO THE HEALTH SECTOR}

The health sector specific problems are of a technical, economic and managerial nature. They include:

- The Development of Insecticide Resistance - While resistance to DDT was detected in anopheline vectors in Greece as early as the 1950 s, there was a strong belief at the time that malaria eradication using residual house spraying could be achieved before this phenomenon would develop into a problem of serious proportions. However, things took a different turn and control programmes had to seek resort in the application of increasingly expensive alternative compounds, which reduced their economic viability before the final goals could be met.

- The Development and Spread of Drug Resistance - Resistance of the malaria parasite to chloroquine, first discovered in the 1970s in South East Asia and East Africa, has subsequently spread to other parts of the world and has been followed by the development of resistance to other antimalaria drugs. On the long term this development undermines the potential contribution of chemotherapy to the control of the disease.

- Resource Constraints on Intervention Programmes - Apart from the above mentioned problems in malaria control, resource constraints in the prevention and control activities aimed at other diseases underscore the continued need for vector control efforts. In the case of schistosomiasis an effective, single dose drug is available, but its cost has, until now, hampered its widespread use in mass chemotherapy. Where it has been used, such as in the long-term trials in selected villages on the island of Leyte in the Philippines, it has been shown that prevalence rates drop to a level that is apparently determined by local environmental and behavioural determinants of transmission (Olveda, in prep.). Sooner or later, managers of control programmes will be faced with the dilemma whether to proceed with expensive mass chemotherapy to treat a relatively small group of infected people or to instate a probably equally expensive case detection system to target drug treatment on infected people only. It is now increasingly recognized that other control methods, including snail control and improved sanitation, will continue to be needed. Another example is Japanese encephalitis, an arboviral disease associated with irrigated rice ecosystems in South and South-East Asia. While a vaccine for this infection is available, its price (US\$10/dose) and the cost of an effective delivery system impede its use in many endemic countries. Again, vector monitoring and control need to be relied on to prevent major outbreaks.

- De-emphasis on Vector Control as a Result of Integration - In many countries the health sector has been re-organized based on the recommendations adopted unanimously by the WHO Member States at the International Conference on Primary Health Care in Alma 
Ata in 1977. These changes include a shift from vertical, single disease oriented programmes to horizontal programmes. As a result, in many countries the activities of malaria control campaigns and other vectorborne disease control programmes have been integrated into the general health services. This change was dictated by the economic realities since the 1970 s and supported by considerations of social justice and equity. In many countries, however, the vector control component of control activities has been reduced disproportionately, to the extent that the question has been raised whether vector control should remain the responsibility of the ministry of health. In some countries (Singapore is a success story in this respect, see Chan Kai Lok and Bos, 1987) vector control has moved to become a responsibility of the ministry of the environment. The loss of profile of vector control has contributed in an important way to current human resource constraints, as professional career perspectives in this area of speciality have lost a great deal of attraction.

The above problems are, by and large, a matter for the health sector to solve; policy modifications linked to programmatic changes, a reformulation of research goals and a redefinition of training objectives are required.

\section{VECTOR-BORNE DISEASE PROBLEMS AND GLOBAL ENVIRONMENT/DEVELOPMENT ISSUES}

A number of global trends on the interface between environment and development have immediate repercussions for the vector-borne disease situation and for the effective implementation of vector control operations. The most important of these trends is, beyond doubt, the continued growth of the human population, expected to reach 6 billion before the year 2000 . This has a range of consequences, each with its own impact on vector ecology, and include:

\section{- Accelerated Development of Natural}

Resources - The continuously rising demand for food, fibre and energy forces national authorities to rapidly develop land and water resources for agricultural production and energy generation. Irrigation schemes and man-made reservoirs may provide new habitats for disease vectors. The adverse environmental consequences of this type of development include deforestation, soil erosion and degradation, desertification and waterlogging. Each of these may also affect the ecology of local vectors and lead to a deterioration of the vector-borne disease situation. As far as the human health dimension of these problems is concerned, it can be attributed, in general terms, to insufficient intersectoral consultation at the early planning stages, inadequate health risk assessment at the time of feasibility studies and the failure to incorporate environmental health safeguards as part of the project during the construction phase. In the end, the health sector is faced with intensified health problems but in its already stretched budget there is usually no room to meet the needs in terms of strengthening of health services.

- Demographic Changes in the Rural Areas Development of natural resources often results in considerable changes in the density, composition, settlement conditions and movement of human populations.

Resettlement prior to the filling of reservoirs, or as part of agricultural development may introduce non-immunes or parasite carriers into new risk areas. Agricultural development may also create new migration patterns of people attracted by the economic opportunities created or of seasonal labourers in relation to the cropping cycle. These demographic changes have the potential to promote the spread of vector-borne diseases, as exemplitied by the spread of schistosomiasis in the middle Awash Valley in Ethiopia (Meskal, 1987). They may also exacerbate the specific health sector problems, as for example in the case of Thailand, where migration has contributed to the spread of chloroquine resistant malaria.

\footnotetext{
- Rapid Urbanization - Attracted by the economic opportunities of the big city, the
} 
movement of rural people to urban centres of the developed countries was an important phenomenon of the 1960s and 1970s. While it continues to make an important contribution to urbanization, by the middle of the $1980 \mathrm{~s}$ it was substituted by the intrinsic growth of urban populations as the first cause of rapid urban expansion. As the municipal authorities cannot keep pace in terms of basic services of drinking water supply, sanitation and solid waste collection, environmental degradation in the big cities inevitably results in increased risks of certain vector-borne diseases: dengue, lymphatic filariasis and, in some cases, malaria. On the basis of trends in urbanization it can be predicted that urban vector control will require a major increase in resources in the next couple of decades.

For the adoption of Agenda 21 the UNCED will address a number of global environmental issues, such as global climatic change, ozone-layer depletion, reduction of biodiversity, desertification and the pollution of the oceans and seas. At least two of these issues have plausible vector ecological implications. Global climatic change may modify the distribution of vector-bome diseases and the dynamics of vector populations. A rise in mean temperatures may push the limits of, for instance, malaria transmission to higher latitudes and altitudes. Changed rainfall patterns may affect the seasonality and distribution of transmission. Changed wind patterns and intensities may contribute to the passive migration of insect vectors. As models for climatic change are still relatively speculative (apart from a global rise in temperatures) and cannot predict changes in local conditions, very little can be said with certainty about its effect on vectorborne disease transmission. Possible effects are presented in Table 1 (WHO, 1990). Monitoring of malaria transmission in sensitive areas (at the altitude limits of transmission) will assist in confirming the expected change.

A reduction in biodiversity may also affect the vector-borne disease situation. Resource development projects invariably lead to habitat simplification, and often favour pest species over their natural enemies. This is true both for agricultural pests and vectors of diseases. The situation may be further exacerbated by the excessive use of pesticides. In particular their use for agricultural purposes which makes up the greatest part $(90 \%)$ of pesticide applications and moreover releases residues in the environment in an indiscriminate manner, affects populations of natural enemies of pest species and leads to the accelerated development of insecticide resistance.

\section{VECTOR CONTROL IN THE CONTEXT OF SUSTAINABLE DEVELOPMENT}

While the term "sustainable development" was not in first used by the World Commission on Environment and Development (WCED, 1987), it deserves credit for the clear definition of the concept, for the review of how the current range of global and local environmental problems is a result of on the one hand unchecked industrial development and on the other hand unacceptable inequity and associated poverty, and for formulating proposals for reforms in policies and institutional arrangements that will contribute to an improvement of the situation. In its report "Our Common Future", the Commission defines sustainable development as development that aims at meeting the needs of the present generation without compromising the ability of future generations to meet their own needs. It cautions that further development should ensure a minimal depletion and destruction of the Earth's resource base and should aim at reducing poverty which is at the root of major environmental degradation.

In putting the control of disease vectors in the context of sustainable development, two points have to be clarified. First of all the human health dimension of environmental problems needs to be better detined. This goes beyond vector-borne diseases: thete are numerous physical and chemical risk factors to human health in the environment.

Dise:se vectors are, however, unique in that they are biological risk factors and therefore capable of adapting to new conditions. This 
FIGURE 1. Possible Effects of Climate Change Due to the Greenhouse Effect on Vector-Borne Disease Epidemiology

Examples of

effects on vector-borne diseases

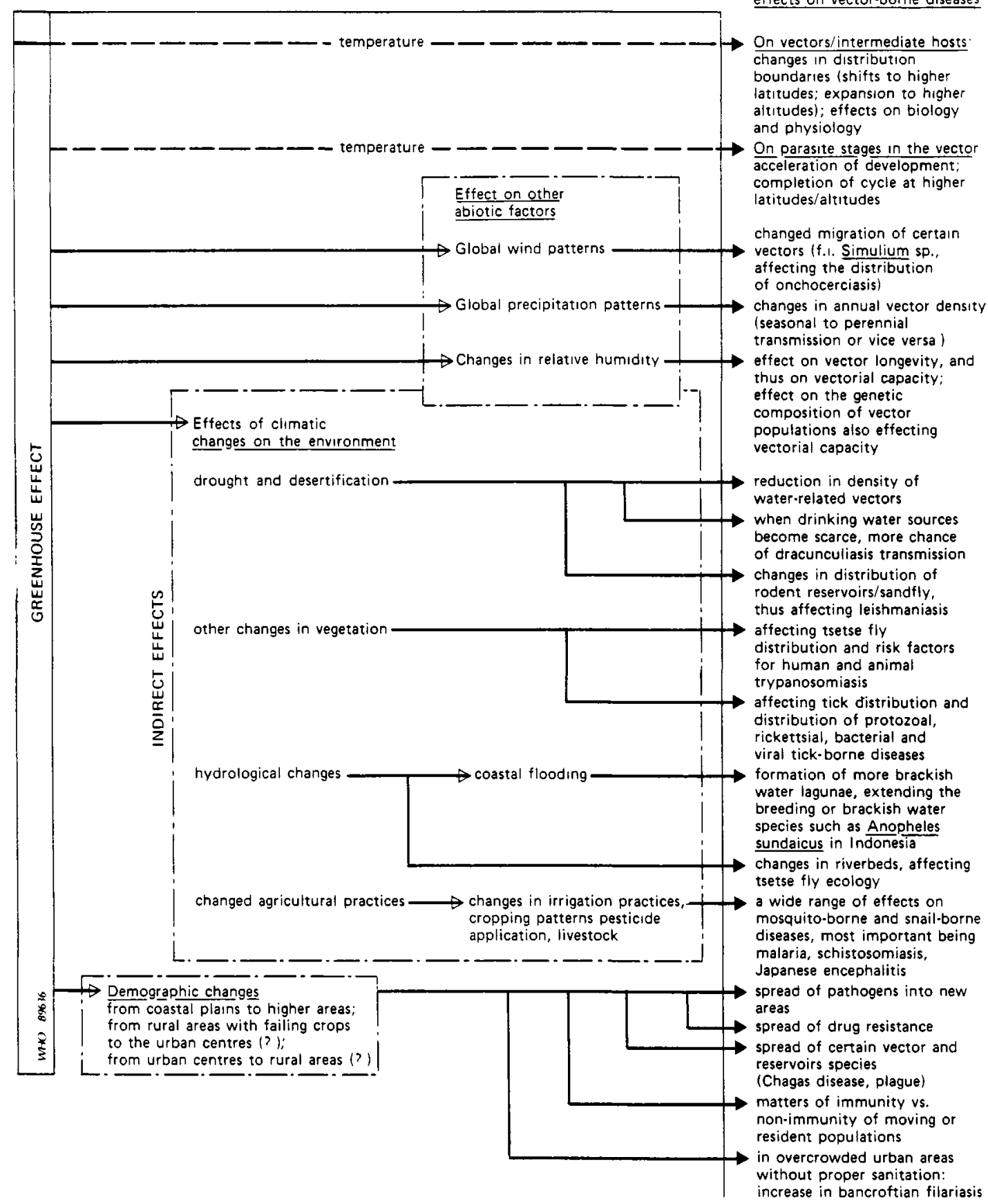


adds to the complexity of the problems they cause. Secondly, the conditions required to operationalize sustainable development principles and approaches in the planning and implementation of vector control need to be outlined. This will be discussed in the remainder of this paper.

As can be concluded from the Brundtland report, the potential of sustainable development comes to expression in a multidisciplinary understanding of the key problems, and the political will to make an intersectoral move towards lasting solutions. For vector control this means that the question is whether, instead of protecting communities from vector-borne disease risks in the traditional, sectoral manner once we are faced with the consequences of development, we can install permanent conditions as a part of development to reduce vector-borne disease hazards to an absolute minimum and with the least possible pressure on the Earth's resources.

These views were recently re-inforced by the WHO Commission on Health and Environment. In its report "Our planet, our health" (WHO, 1992) it extends the relationship between development and the environment with the explicit repercussions for the human health status. Under the heading Food and Agriculture the Commission recommended, inter alia, that more research should be carried out on how to increase food production in the tropics while reducing tropical diseases and harmful effects on the environment and in a separate section on water issues it stressed that the priority for water pollution control in the world is the control of bacteriological and parasitic water-borne diseases.

\section{AREAS IN WHICH THE NEW APPROACH SHOULD TAKE EFFECT}

Four areas can be distinguished where new initiatives may contribute to the incorporation of principles of sustainable development in vector control:
- Modifications in the policy framework;

- Expansion of our knowledge base;

- Development of operational methods and techniques;

- A shift in emphasis in training and education.

\section{Policy Matters}

The decision-making processes leading up to development project are guided by government policies and, whenever external support is required, by policies of bilateral and multilateral development agencies. Government policies are hierarchically structured. Macro-economic policies at the national level are translated into sectoral policies as the basis for programmes of individual ministries. A recent literature review by WHO and the World Bank of the health impact of development policies (Cooper-Weil et al., 1991) revealed a range of inadvertent consequences on the human health status of agricultural, industrial, energy and housing policies. The cause-and-effect relationship between macro-economic policies, sectoral policies and the human health status is also raised by the WHO Commission on Health and Environment (WHO, 1992). In many cases the linking factors are environmental determinants of health. In 1989 the WHO/FAO/UNEP Panel of Experts on Environmental Management for Vector Control (PEEM) carried out a similar policy review in the narrower context of the effects of water resources development on vectorborne disease transmission (Mather and Bos, 1989). Policies involved may be as diverse as guidelines for equitable distribution of water in irrigation schemes or the use of the Internal Rate of Return as the major criterion at the appraisal phase of development projects. At the same time, health sector policies may not be conducive to the establishment of an intersectoral dialogue and impede optimal participation of health sector staff in intersectoral efforts of problem solving.

\section{Insufficient Knowledge Base}

The emphasis on chemical methods of 
vector control after the Second World War is reflected in the research priorities during those decades and continues to be felt. As a result, there is a bias towards information on issues such as vectorial behaviour with relevance to indoor wall spraying campaigns (exophily/exophagy versus endophily/endophagy), genetic mechanisms of insecticide resistance or the relative effectiveness of different types of insecticide application. At the same time, there has been a dearth of studies on vector ecology and particularly on the nature of the association between land and water resources development, environmental change and vector population dynamics. This is true as well for the epidemiological dimension of environmental approaches to vector control: there is a great need to better define under which conditions a reduction in population densities will be effective or not. A new attitude is required: rather than thinking in terms of a universally applicable method, researchers have to start thinking in terms of characterization of local eco-epidemiological situations and design "custom-made" environmental interventions for each specific case.

\section{Inadequate Operational Methods and Techniques}

In order to be able to participate in the planning of development projects and in the design of health safeguards that are an integral part of such developments, vector specialists need new methods and techniques. Environmental Impact Assessment is now part of most feasibility studies, and health risk assessment should be integrated into this. Health sector professionals must be ready to work with engineers in rapid appraisal exercises. A methodology for such an appraisal is proposed in guidelines that have been produced by the WHO/FAO/UNEP PEEM (Birley, 1989). Once the risks are identified, options for health safeguards, monitoring and surveillance and control have to be analyzed for their cost-effectiveness.

The results of this analysis have to be presented at the time of economic appraisal of the project. Monitoring and surveillance during the construction phase should confirm the initial forecast and detect any unexpected health effects requiring interventions. The development of remote sensing techniques and the use of geo-referenced databases will be of strong support to overall monitoring.

\section{Re-Direction of Training and Education}

Tertiary education is aimed at the formation of professionals in sharply defined disciplines. As a result communication between professionals of different disciplines is often difficult. They have been trained neither to appreciate the opportunities that are available in other disciplines, nor to understand the constraints faced by professionals in other fields. A re-direction of training does not imply making a vector specialist out of an engineer or vice versa, but it should help to develop the capacity of professionals to work in multidisciplinary teams in a problemoriented approach. Rather than expanding detailed knowledge of individual experts beyond their area of speciality, professionals should know where to go to obtain available information when it is needed. This requires changes in University course curricula and the introduction of problem-based learning techniques.

Community education should also become more intersectoral. Specific health subjects are usually effectively disseminated to the community level by the traditional health education systems. However, it is unlikely that a farmer will accept directives on changes in agricultural practices which are to contribute to improved environmental health conditions if they come from a health educator. Alternative and more appropriate vehicles for such messages need to be used, such as, in the case of the above example, agricultural extension programmes. Efforts to promote this intersectoral approach in community education are underway and will soon be tested in a number of countries.

\section{RECOMMENDATIONS}

Based on the above, a number of additional 
recommendations are recommended for incorporation into the document under preparation at the Conference, under the general heading of intersectoral collaboration:

- Policies of the ministries involved in natural resources development (agriculture, energy, water resources etc.) should be reviewed for their possible effect on the environmental determinants of human health and where necessary adjustments should be negotiated;

- Planning procedures of new resource development projects should include early, intersectoral consultation as well as an environmental impact assessment that includes a human health component beyond the strict health sectoral interests; resources should be allocated to ensure the incorporation of the most cost-effective health safeguards into the project design and implementation;

- Multidisciplinary research on disease vectors and vector-borne disease epidemiology should be promoted as a joint endeavour of health, agricultural and environmental research institutions;

- In the course curricula of professionals in health sciences and those who will work in development projects, awareness creation of environmental health problems and training in multidisciplinary, problem oriented team work should be included;

- Alternative, potentially more effective vehicles for community education on environmental management measures for vector control, such as the agricultural extension system, should be tested and employed.

\section{RESUMO}

BOS, R. Novas Abordagens ao Controle de Vetores de Doenças no Contexto do Desenvolvimento Sustentável. Cad. Saúde Públ., Rio de Janeiro, 8 (3): 240-248, jul/set, 1992.

Devido a problemas cspecificos do setor saúde, bem como a problemas associados a questōes de manutenção, os programas para o controle de doenças transmitidas por vetores estão cada vez mais retornando à adoção de práticas de manejo ambiental para reduzirem populações de vetores, como parte de uma abordagem de controle integrada. Os problemas mais gerais advindos da interface entre ambiente e desenvolvimento que necessitain ser abordados no contexto do controle de vetores incluem a acelerada exploração de recursos naturais, mudanças demográlicas em populações rurais e a rápida urbanização. Os vetores de doenças devem ser reconhecidos como fatores biológicos de risco no ambiente para a saúde humana. Para uma implementação sustentável das inedidas de controle de vetores, estes aspectos devem fazer parte do processo de desenvolvimento. Isto requer modificações na formulação de políticas, aumento da nossa base de conhecimento acerca destes processos, desenvolvimento de métodos e técnicas operacionais, assim como uma maior ènfase em treinamento e educação.

Palavras-Chave: Vetores; Ambiente; Políticas de Desenvolvimento; Desenvolvimento Sustentável

\section{REFERENCES}

BIRLEY, M. H., 1989. Guidelines for the forecusting of vector-borne disease implications of water resources development. PEEM guidelines series no 2, Geneva: PEEM Secretariat, World Health Organization.

CHAN KAI LOK \& BOS, R., 1987. Control of dengue vectors: Singapore's success story. World Health Forum, 8: 101-102.

COOPER-WEIL, D. E.; ALICBUSAN, A. P.; WILSON, J. F.; REICH, M. R. \& BRADLEY, D. J., 1990. The impact of development policies on health. Geneva: World Health Organization. 
MATHER, T. H. \& BOS, R., 1989. Policies and programmes of governments, bilateral and mulitlateral agencies and development banks for environmental management in the context of natural resources, agriculture and health development. Unpublished document VBC/89.7, Geneva: PEEM secretariat, World Health Organization.

MESKAL, F. H., 1987. Vector-borne diseases related to labour movement and arrangements for their control. In: Selected working papers prepared for the third, fourth, fift and sixth meetings of the WHO/FAO/UNEP Panel of Experts on Environmental Management for Vector Control. Unpublished document VBC/87.3. Geneva: PEEM Secretariat, World Health Organization.

OLVEDA, R. M.; DANIEL, B.; RAMIREZ, B.; FEDIVAL, P.; TIU, E.; DE VEYRA, F.; ACOSTA, L.; PETERS, P.; ROMULO, R.; DOMINGO, E. \& OLDS, G. R., (in prep.). Longitudinal studies of schistosomiasis japonica in the Philippines: the long term impact of annual chemotherapy on infection, transmission and morbidity.
WHO (Commission on Health and Environment), 1992. Our planet, our health. Geneva: World Health Organization.

WHO (Commission on Environment and Development), 1987. Our common future . Oxford: Oxford University Press.

WHO (World Health Organization), 1990. Potential health effects of climatic change. Report of a WHO Task Group. Geneva: World Health Organization.

1991. World Health Magazine (issue on malaria), $\mathrm{n}^{\circ} 7$. 